\title{
ALOI, Michael J., FUSCO, Marjorie and KETCHAM, Susan E. Digital collections worldwide: An annotated directory. New York: Neal-Schuman. 2011. 366 pages. ISBN-13 978155570701 9. \$255.00.
}

This text represents an ambitious attempt to bring one of the best examples of the print-based reference tradition - the annotated directory - to bear on the fluid, dynamic world of digital collections. The scale of the undertaking and the quantity and variety of the resources cited is impressive, with descriptions of more than 1,000 individual digital collections covering a wide range of topics and formats. It provides details, together with concise yet informative annotations, for digital collections of materials including books, newspapers, maps, postcards, photographs, archives, speeches, multimedia materials, websites and museum artefacts. Although collections from museums, galleries and archives are included, the emphasis lies heavily on digital collections from libraries.

The book is clearly structured. It begins with a "Preface" which highlights some of the challenges presented by digital content: the limitations of online search engines, the perils of dead links and the difficulty of determining authenticity and provenance in the world of online resources. The purpose of the text is clearly described - aiming to provide information about "authoritative, useful and permanent worldwide digital collections" (p.xvi) - and the selection criteria are outlined. However, some of the criteria decisions could be better explained: why are scholars' personal websites treated as authoritative sources of collections alongside government bodies, libraries and museums? Why include "the personal website of an individual who lived in Bolivia as a foreign-exchange student" (p.304) but not include a discussion of social media sites which facilitate new types of digital collection building and access provision by a wide range of people and organisations, including cultural and heritage institutions? A direct definition of what constitutes a "digital collection" would also be helpful, although the authors provide this implicitly when they write of "digital objects... organized, categorized, and classified to create like sets of materials" (p.xviii).

The first chapter gives a summary of "World Initiatives" and it is followed by seven further chapters, each covering one continent. A brief introductory text describes each continent, followed by a description of continent-wide digital collection initiatives and then moving alphabetically through each country and any relevant subdivisions, such as the home nations of the UK, and each of the 50 states (plus Washington, DC) for the USA. This structure, supplemented by two indexes, one listing the collections described and one combining subjects, names and titles, makes the text easy to navigate.

One very positive feature of this directory is the inclusion of non-English language collections, providing that they can be translated using online language tools. However, the overwhelming majority of the resources described are primarily available in English and many of the entries include collections hosted in the United States in particular. Given that this a US publication, this is understandable, and the North American section - the largest in the book and only slightly shorter in length than the chapters for Asia, Africa and Europe combined - is particularly strong, providing an excellent level of detail and depth, and including details of more than 100 digital collections provided by the Library of 
Congress. However, this does raise the question of whether the title Digital collections worldwide is entirely accurate, or whether what the authors are offering the reader might be described better as the world in digital collections. Some unexpected inclusions highlight this ambiguity: the CIA World Factbook is cited in four country entries, despite the difficulty - for this reader at least - of treating that work as a collection. Of 19 collections selected to represent the mainland of China (People's Republic of China), most (15) are maintained by organisations in the United States. Although reference is made in a couple of earlier entries to articles describing Chinese digital library projects, a brief overview of this work - and similar projects in other countries - could have enriched the global picture offered by this text. Similarly, 6 collections cited for Russia are hosted in the US, whilst the digital collection of the State Hermitage Museum in St Petersburg is omitted. There are some surprising omissions in the entries for the UK: the British Library is included, but there is no entry for the British Museum, the National Gallery, or the National Archives, although all do have digital collections. The Victoria and Albert Museum appears as the single entry under "England", whilst the resource list for "Scotland" includes Aberdeen Art Gallery and Museums, but not the National Museum of Scotland or the National Galleries of Scotland.

There are also significant variations in the scale, type and methods of generating some of these collections. For example, the entry for Comoros comprises a single item from the World Digital Library, whilst other "collections" are in fact sets of search results. Arguably the richest digital collection of European cultural materials - Europeana - makes only one appearance and that is somewhat perplexingly under the country entry for Iraq ("A search for Iraq retrieved over 1,200 items..." p.86).

Although the prefatory text claims that subject guides and pathfinders are not included, in reality a number of resources are digital versions of the traditional subject guide, such as the University of Miami Libraries' LibGuides resource listings for "East and Southeast Asian studies - Taiwan".

Unfortunately, the problem posed by broken links is also clearly apparent in this book. One key collection, Portals to the World by the Library of Congress, was suspended in September 2010. The fact that it is still listed in this text reflects the long lead-in times for print publications and the challenge this creates for any print-based reference work dealing with digital resources. The text's companion website provides more up-to-date information about the availability of each individual resource. At the time of writing (July 2012) the most recent updates had been made in February. However, the process of simultaneously consulting the printed text and accessing the companion website (which lacks a search facility or any equivalent of the book's dual index) for the most accurate link information can prove somewhat cumbersome. In this respect at least it might have been better published as an e-book - it would certainly make a useful digital collection in its own right.

\section{Angharad Roberts}

Library Operations Manager, Barts Health NHS Trust angharad.roberts@bartshealth.nhs.uk 